\title{
Diagonal Cracking Capacity and Ultimate Shear Strength of Slender RC Beams without Web Reinforcement
}

\author{
Mohammed Shukri Al-Zoubi \\ Department of Civil and Environmental Engineering, Faculty of Engineering, Mutah University. \\ E-Mail: malzoubi@mutah.edu.jo
}

\begin{abstract}
This study presents a method that combines both dimensional analysis and statistical regression analysis for predicting the shear capacity of slender reinforced concrete (RC) beams without web reinforcement taking the size effect into consideration. This method incorporates the modified Buckingham-PI theorem (Butterfield, 1999, Geotechnique 49(3), 357-366) to formulate two mathematical models for predicting the shear capacity at the formation of diagonal tension cracks and at the ultimate shear strength. The results of the two models are compared with several sets of existing experimental results. This study shows that the variations in the experimental results of shear capacity of slender RC beams $(a / d>2.5)$ defined at the formation of diagonal tension cracks of beams can be explained by the variations of the concrete tensile strength and the variations in the experimental results of ultimate shear strength of slender RC beams $(a / d>2.5)$ can be explained by the variations of the concrete splitting strength.
\end{abstract}

KEYWORDS: Reinforced concrete beams, Diagonal tension cracking, Moment capacity, Ultimate shear strength, Concrete tensile strength, Concrete splitting strength.

\section{INTRODUCTION}

Many concrete structural members such as slabs and foundations do not use shear reinforcement. Hence, knowledge of shear carrying capacity of reinforced concrete (RC) beams without web reinforcement is necessary in these cases (Rebeiz et al., 2000). Furthermore, most theoretical and experimental studies on beams without web reinforcement also provide useful insights for the explanation of failure mechanism in beams with stirrups (Zararis and Papadakis, 2001) particularly in the availability of large shear database for reinforced concrete members without shear reinforcement (e.g., Reineck et al., 2003). Reinforced concrete beams without web reinforcement may, depending on the shear span to

Accepted for Publication on 6/11/2013. depth ratio $a / d$ (Fig. 1), fail in different modes including failure due to flexure, shear compression, diagonal tension cracking, concrete splitting of the compression zone, bond or anchorage. For RC beams with shear span to depth ratio $a / d$ greater than about 6 , failure is generally governed by flexure whereas for RC beams with $a / d$ of less than about 6 , failure is initiated by the formation of diagonal tension cracks in the shear span. RC beams with $2.5<a / d<6$ generally fail upon the formation of diagonal tension cracks when the tensile concrete strength is reached or shortly afterwards (MacGregor, 1997) when concrete splitting strength of the compression zone is reached (Zararis and Papadakis, 2001); whereas beams with $a / d$ of less than about 2.5 may carry additional loads in excess of those that cause the diagonal tension cracks due to arch action (MacGregor, 1997).

Various approaches or models are available in the 
literature for the evaluation and/or determination of the shear strength of RC beams (e.g., Clark, 1951; Van Den Berg,1962; Zsutty, 1968, 1971; Bazant and Kim, 1984; Vecchio and Collins, 1986; Hsu et al., 1987; Adebar and Collins, 1996; Collins et al., 1996; Reineck, 1991; Kim and Park, 1996; Rebeiz, 1999; Zararis and Papadakis, 2001; Russo et al., 2005; Bentz et al., 2006; AASHTO LRFD, 2004; CSA A23.3-2004; ACI318-2008; Arslan, 2008, 2010, 2012; Appa Rao and Injaganeri, 2011). Despite the useful and valuable results reported in literature for the shear behavior of $\mathrm{RC}$ beams and factors affecting their shear failure (e.g., ACI 445R-99), a fundamental theory explaining the mechanism of shear failure of beams is still missing or unresolved (Zararis and Papadakis, 2001; Zararis, 2003) as evidenced by the differences between experimental results and theoretical analysis. As a result, the available methods (including international codes such as the AASHTO LRFD, 2004; CSA A23.32004; ACI318-2008) are based on a rather empirical or semi-empirical consideration. Hence, a dimensional analysis along with statistical regression analysis may be suitable for predicting the behavior of RC beams and can be used to give reasonably well predictions and sufficiently accurate method of analysis if the appropriate governing variables are considered. For example, Phatak and Dhonde (2003) successfully formulated a general expression for the ultimate torsional capacity of RC beams subjected to pure torsion using dimensional analysis by the modified Buckingham-PI theorem (Butterfield, 1999). Zsutty (1968) also developed a model based on dimensional analysis for the shear capacity of slender RC beams with depth $d \leq 50 \mathrm{~cm}$ without considering the size effect. The Zsutty (1968) model may give reasonable predictions for slender RC beams with $d \leq 50 \mathrm{~cm}$; however, the Zsutty (1968) model may overestimate the shear capacity for large RC beams $(d \geq 50 \mathrm{~cm})$ as will be shown later in this paper.

In this study, the shear capacity of slender reinforced concrete beams without web reinforcement having shear span to depth ratio $a / d>2.5$ under the combined action of moment and shear taking the size effect into consideration is evaluated at the formation of diagonal tension cracks and at ultimate shear failure by using a method that combines both dimensional analysis and statistical analysis. Several sets of experimental data were carefully selected such that the influence of each basic variable (i.e., longitudinal steel ratio $\rho$, concrete compressive strength $f_{c}^{\prime}$, shear span to depth ratio $a / d$ or beam size $d$ ) can be separately evaluated. Comparison with existing experimental results as well as with four existing models supports the validity of the two proposed models in predicting and explaining the observed behavior of slender RC beams ( $a / d \geq 2.5$ ) without web reinforcement.

\section{Dimensional and Regression Analysis for RC Beams for Different Modes of Failure}

Dimensional analysis by the modified BuckinghamPI theorem (Butterfield, 1999) is used in this study to evaluate the behavior of slender RC beams without web reinforcement. The goal of dimensional analysis is to minimize the dimension space in which the behavior of a certain system might be studied by systematically combining the assumed governing $n$ variables $V A R=\left(V_{1}, V_{2}, V_{3}, . ., V_{n}\right)$, involving a total of $m$ independent primary dimensions $D=\left(D_{1}, D_{2}, D_{3}, . ., D_{m}\right)$, into $N(=n-m)$ dimensionless groups (Phatak and Dhonde, 2003) as demonstrated in the following subsection.

\section{Slender RC Beams ( $a / d>2.5)$ at the Formation of Diagonal Tension Cracks without Size Effect}

Dimensional analysis first requires identifying the set of the appropriate governing variables and then the set of independent primary dimensions. The shear capacity $v_{c r}$ of slender RC beams without web reinforcement at the formation of diagonal tension cracking without considering size effect is dependent on three governing variables: the longitudinal reinforcement ratio $\rho$, shear span to depth ratio $a / d$ and concrete tensile strength $f_{c t}^{\prime}$ (Zsutty, 1968). Hence, the set of variables may be expressed for 
slender RC beams without considering the size effect as follows:

$$
\text { Variables }=\left(v_{c r}, f_{c t}^{\prime}, a / d, \rho\right)
$$

Therefore, $n=4$ and the set of dimensions of these $n$ variables can be written as follows:

$$
\text { Dimensions }=\left(M^{1} L^{-1} T^{-2}, M^{1} L^{-1} T^{-2}, 0,0\right)
$$

Thus, the number of independent primary dimensions is:

$$
m=3 \text {. }
$$

The condition of $D_{\min }$ is satisfied by minimizing the value of total number of primary dimensions $m$ and thus accounting for the greatest number of dimensionless groups possible (Phatak and Dhonde, 2003). Therefore, assuming that $F=M^{1} L^{-1} T^{-2}$, then:

$D_{\text {min }}=(F, F, 0,0)$.

(4)

Hence,

$m_{\min }=1$.

The number of repeating variables forming a set of $\mathrm{Q}$ is equal to $m_{\min }=1$. Thus, the number of dimensionless Pi-groups is equal to $N(=n-m)=4-1=3$, which is also the same as the number of isolated variables. Let $\mathrm{R}$ be the set of variables (in Eq. 1) that have dimensions totally distinct from each other, therefore,

$$
R=\left\{v_{c r}\right\}
$$

Dimensionless groups are formed by the combination of the repeating (Q) and isolated (NOTQ) variable sets (Phatak and Dhonde, 2003). Q is to be selected from $\mathrm{R}$, therefore, $\mathrm{Q}$ may be taken as follows:
$Q=\left\{v_{c r}\right\}$

Using Eq. 7, isolated variables $=\left\{f_{c}^{\prime}, a / d, \rho\right\}$ and repeating variables $=\left\{v_{c r}\right\}$. Therefore, the dimensionless groups may be represented as follows:

$$
\begin{aligned}
& \pi_{1}=\left(v_{c r}, f_{c t}^{\prime}\right) \\
& \pi_{2}=\left(v_{c r}, \rho\right) \\
& \pi_{3}=\left(v_{c r}, a / d\right) .
\end{aligned}
$$

Thus, the dimensionless group $\pi_{1}=v_{c r}{ }^{a} f_{c t}^{\prime b}$ may be expressed in dimensional form as:

$$
M^{0} L^{0} T^{0}=\left[M^{1} L^{-1} T^{-2}\right]^{a}\left[M^{1} L^{-1} T^{-2}\right]^{b} .
$$

Hence, $a=1$ and $b=-1$, therefore,

$\pi_{1}=\frac{v_{c r}}{f_{c t}^{\prime}}$

Similarly, for the other two dimensionless $\pi$ groups:

$\pi_{2}=\rho$.

$\pi_{3}=\frac{a}{d}$

Expressing these three $\pi$ dimensionless groups by using a power-product relationship, the following expression may be obtained (i.e., $\pi_{1}=A 1\left(\pi_{2}\right)^{B 1}\left(\pi_{3}\right)^{C 1}$ )

$\frac{v_{c r}}{f_{c t}}=A 1 \rho^{B 1}\left(\frac{a}{d}\right)^{C 1} ;$

where $A 1, B 1$ and $C 1$ are constants.

The concrete tensile strength $f_{c t}^{\prime}$ may be expressed as a function of the concrete compressive strength $f_{c}^{\prime}$ as follows:

$f_{c t}=D 1\left(f_{c}^{\prime}\right)^{E 1}$

Hence, the shear capacity of slender RC beams defined at the formation of diagonal tension cracks 
without size effect may be expressed as follows:

$$
v_{c r}=K 1 \rho^{B 1}\left(f_{c}^{\prime}\right)^{E 1}\left(\frac{a}{d}\right)^{C 1} .
$$

Equation 17 may be expressed in a logarithmic form to allow the use of multiple linear regression analysis as follows:

$\log v_{c r}=\log K 1+B 1 \log \rho+E 1 \log f_{c}^{\prime}+C 1 \log \frac{a}{d} \quad ;$

where $A 1, B 1, C 1, D 1, E 1$ and $K 1$ are constants to be determined empirically by multiple linear regression analysis using the shear capacity of slender RC beams $(a / d>2.5)$ without web reinforcement at the formation of diagonal tension cracking. Zsutty (1968, 1971), based on a similar analysis, suggested the following empirical expression:

$$
\begin{aligned}
& v_{c r}=\frac{V}{b d}=60\left(\rho f^{\prime}{ }_{c} \frac{d}{a}\right)^{1 / 3} \text { in psi units } \\
& v_{c r}=\frac{V}{b d}=2.2\left(\rho f^{\prime}{ }_{c} \frac{d}{a}\right)^{1 / 3} \text { in MPa units. }
\end{aligned}
$$

As can be seen, the Zsutty model is independent of the beam size and is valid only for the sizes of beams (i.e., $d \leq 50 \mathrm{~cm}$ ) that were utilized to develop this empirical model as will be shown later in this study.

\section{Slender RC Beams $(a / d>2.5)$ at the Formation of Diagonal Tension Cracks with Size Effect}

The beam size is an important factor affecting the shear strength of slender RC beams. There is strong evidence (Leonhardt and Walther, 1962; Kani, 1967; Bhal, 1968; Taylor, 1972; Walraven, 1978; Chana, 1981; Shioya et al., 1989; Bazant and Kazemi, 1991; Collins and Kuchma, 1999) that the shear strength of beams decreases as the depth of the beam becomes larger. In order to take the beam size into consideration, the shear capacity $v_{c r}$ of slender RC beams without web reinforcement at the formation of diagonal tension cracking is assumed herein to be dependent on four governing variables: the longitudinal reinforcement ratio $\rho$, shear span to depth ratio $a / d$, concrete tensile strength $f_{c t}^{\prime}$ and beam size $d$. Hence, the set of governing variables may be expressed for slender RC beams including the size effect as follows:

Variables $=\left(v_{c r}, f_{c t \xi}, a / d, \rho\right)$.

The size effect law (Bazant and Kim, 1984) is suggested to be applied directly to the concrete tensile strength as follows:

$$
\begin{aligned}
& f_{c t \xi}=D 2 \xi\left(f_{c}^{\prime}\right)^{E 2} \\
& \xi=\frac{1}{\sqrt{1+d / d_{0}}}
\end{aligned}
$$

where $D 2$ is constant and $d_{0}$ is defined in terms of the maximum aggregate size $d_{a}$ as $d_{0}=25 d_{a}$ (Bazant and Kim, 1984).

Based on dimensional analysis using modified Buckingham theory (Butterfield, 1999) similar to the analysis described earlier, the following expression may be obtained:

$v_{c r}=K 2 \xi \rho^{B 2}\left(f_{c}^{\prime}\right)^{E 2}\left(\frac{a}{d}\right)^{C 2} ;$

where $A 2, B 2, C 2, D 2, E 2$ and $K 2$ are constants to be determined empirically.

The following equation is suggested in this study for the shear capacity of slender $(a / d>2.5)$ RC beams without web reinforcement at the formation of diagonal tension cracks taking the size effect into consideration:

$$
\begin{aligned}
& v_{c r}=\frac{V}{b d}=70 \xi\left(\rho f^{\prime}{ }^{\prime} \frac{d}{a}\right)^{1 / 3} \text { in psi units } \\
& v_{c r}=\frac{V}{b d}=2.6 \xi\left(\rho f^{\prime}{ }^{\prime} \frac{d}{a}\right)^{1 / 3} \text { in MPa units. }
\end{aligned}
$$

\section{Slender RC Beams $(a / d>2.5)$ at Ultimate Shear Strength with Size Effect}

The shear capacity of slender RC beams without web reinforcement at the formation of diagonal tension cracking is mobilized when the concrete tensile strength is reached. Still, the beam can carry additional loads after the formation of diagonal tension cracking 
by the compression zone above the neutral axis. Therefore, the ultimate shear strength of slender RC beams without web reinforcement may be attained after the formation of diagonal tension cracking when the concrete splitting strength $f_{s p}$ of the compression zone is reached (Zararis and Papadakis, 2001). Hence, the ultimate shear strength is dependent on the longitudinal reinforcement ratio $\rho$, span to depth ratio $a / d$, concrete splitting strength $f_{s p}$ and beam size $d$. Therefore, the sets of variables may be expressed for slender RC beams taking into consideration the size effect as follows:

Variables $=\left(v_{u}, f_{s p \xi}, a / d, \rho\right)$.

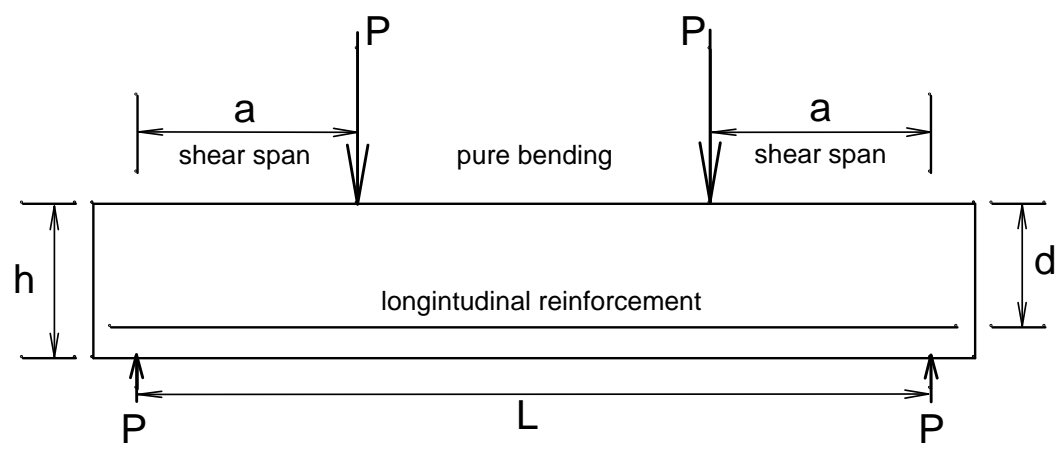

Figure (1): Typical simply supported reinforced concrete beam under two-point loading

Based on dimensional analysis using the modified Buckingham-PI theory (Butterfield 1999), the following expression may be obtained for the ultimate shear strength:

$$
\begin{aligned}
& \left(\frac{v_{u}}{f_{s p \xi}}\right)=A 3 \rho^{B 3}\left(\frac{a}{d}\right)^{C 3} \\
& f_{s p \xi}=D 3 \xi\left(f_{c}^{\prime}\right)^{E 3} \\
& v_{u}=K 3 \xi \rho^{B 3}\left(f_{c}^{\prime}\right)^{E 3}\left(\frac{a}{d}\right)^{C 3} .
\end{aligned}
$$

The following expression is suggested in this study for the ultimate shear strength of slender RC beams ( $a / d>2.5$ ) without web reinforcement taking the size effect into consideration:

$$
\begin{aligned}
& v_{c r}=\frac{V}{b d}=85 \xi\left(\rho f_{c}^{\prime} \frac{d}{a}\right)^{1 / 3} \text { in psi units } \\
& v_{c r}=\frac{V}{b d}=3.2 \xi\left(\rho f_{c}^{\prime} \frac{d}{a}\right)^{1 / 3} \text { in MPa units. }
\end{aligned}
$$

\section{Comparison between Ultimate and Cracking Shear Strengths}

The ratio of the ultimate shear strength (Eq. 29) to the cracking shear capacity at the formation of diagonal tension cracks (Eq. 24) is about 1.22. This value is within the range obtained from the experimental results of slender RC beams of Fig. 2, which shows the variation of ultimate shear strength $V_{u} / b d \sqrt{f_{c}^{\prime}}$ as a function of cracking shear capacity $V_{c r} / b d \sqrt{f_{c}^{\prime}}$.

The variation or scatter observed in Fig. 2 may be due the differences (between and within the tests series) in the definition and identification of the cracking shear and in the representation of the concrete compressive strength (Zsutty, 1968). Furthermore, it is difficult, in many cases, to differentiate experimentally between the shear capacity at the formation of diagonal tension cracking and the ultimate shear strength at beam failure; the same values for the ultimate and 
cracking shear strengths have been reported for a evidenced in Fig. 2. considerable number of slender RC beams as

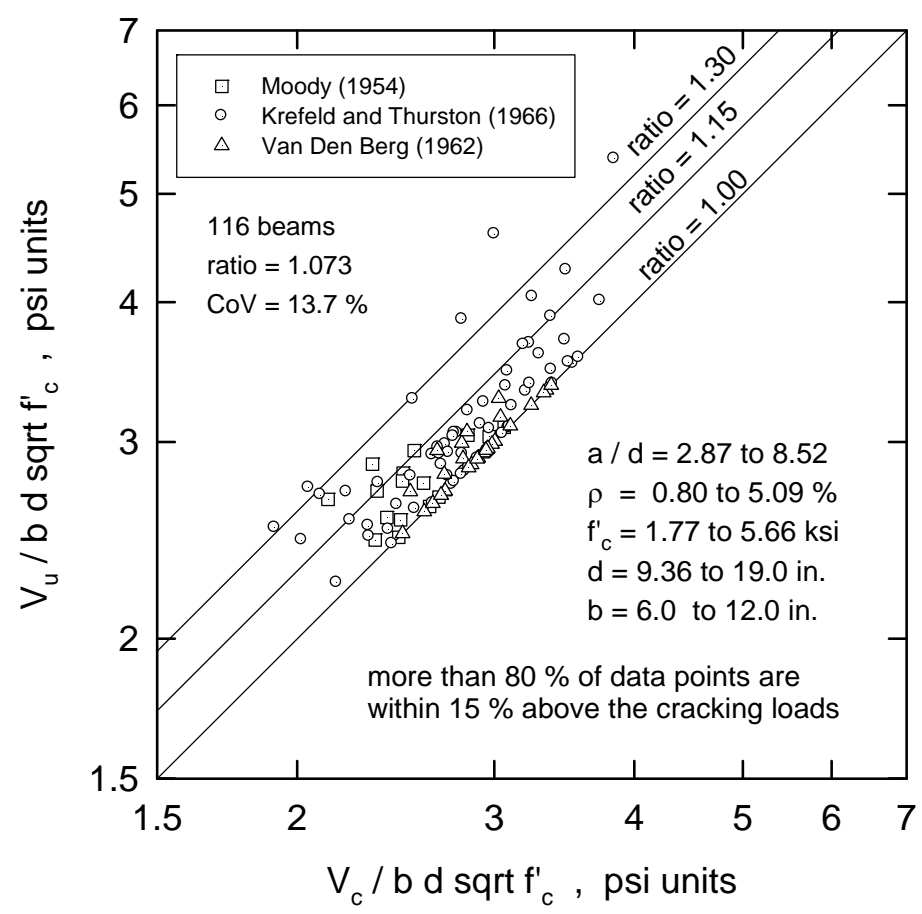

Figure (2): Comparison between ultimate shear strength and cracking shear capacity for 116 beams without web reinforcement

Slender RC beams, with $2.5<a / d<6$, generally fail upon the formation of diagonal tension cracks or shortly afterwards (MacGregor, 1997). Diagonal tension cracks are expected to form when the diagonal tensile stress becomes equal to concrete tensile strength. However, slender RC beams may fail after the formation of diagonal tension cracks when concrete splitting strength of the compression zone is reached (as may be deduced from the work of Zararis and Papadakis, 2001). Hence, the ratio between the ultimate and cracking shear strengths may also be interpreted on average as the ratio between the concrete splitting strength that may be given by $f_{s p}=6 \sqrt{f_{c}^{\prime}}$ and the concrete tensile strength that may be taken as $f_{c t}=5 \sqrt{f_{c}^{\prime}}$. Figure 3 shows that the experimental results of slender RC beams (Mphonde and Frantz,
1984) are practically within the range or limits provided by the two models presented in Eq. 24 for the cracking shear capacity (as a lower limit) and in Eq. 29 for the ultimate shear strength (as an upper limit). Additional experimental results are provided later in this study for supporting the validity of the two proposed models.

\section{Validity of the Proposed Models: Comparison with} Experimental Results and Other Existing Models

Several sets of existing experimental results on shear capacity at the formation of diagonal tension cracking and on ultimate shear strength of slender RC beams are utilized herein to show the capability of the two proposed models in predicting the observed behavior and variations of the experimental results with 
different governing variables. Each set was carefully selected in order to examine the influence of one single variable at a time. Furthermore, four expressions for computing the shear capacity of slender RC beams without web reinforcement (Zsutty, 1968; MCFT of Vecchio and Collins, 1986; Zararis and Papadakis, 2001; ACI 318-08) have been selected in order to verify and compare the two proposed models with these existing models.

\section{Influence of Shear Span- Depth Ratio a/d on Cracking and Ultimate Shear Strengths}

Figures 4 and 5 compare the variation of $V / \sqrt{f^{\prime}} b d$ as a function of shear span - depth rati ( $a / d$ value) of the proposed cracking and ultimate shear strengths with experimental results (Kani, 1967; Bukhari and Ahmad, 2007) as well as with the models of Zsutty (1968) and Zararis and Papadakis (2001); other variables ( $\rho, f^{\prime}{ }_{c}$, and $d$ ) are being practically constant as shown in the figures. As can be seen, the experimental ultimate shear strength decreases drastically as the $a / d$ value increases from 1 to about
2.5 after which the shear strength decreases much more slowly. Figures 4 and 5 show that deep RC beams $(a / d<2.5)$ can carry large additional loads after the formation of diagonal tension cracking by arch action.

Figures 4 and 5 also show that, for slender RC beams ( $a / d \geq 2.5$ ), the experimental results are within the range or limits provided by the two models proposed for the shear capacity at the diagonal tension cracking (as a lower limit) and for the ultimate shear strength (as an upper limit). Furthermore, the values of the cracking and ultimate shear strengths are quite comparable to those of the models of Zsutty (1968) and Zararis and Papadakis (2001).

It should be pointed out that the Zsutty (1968) model is independent of the beam size $d$ (i.e., shear capacity is constant with $d$ ). It is thus expected that this model may give reasonable results for beams with $d \leq 50 \mathrm{~cm}$ because this model was developed empirically for such beams. The Zsutty (1968) model may significantly overestimate the shear capacity for large beams $(d>50 \mathrm{~cm})$ as will be illustrated later in this paper.

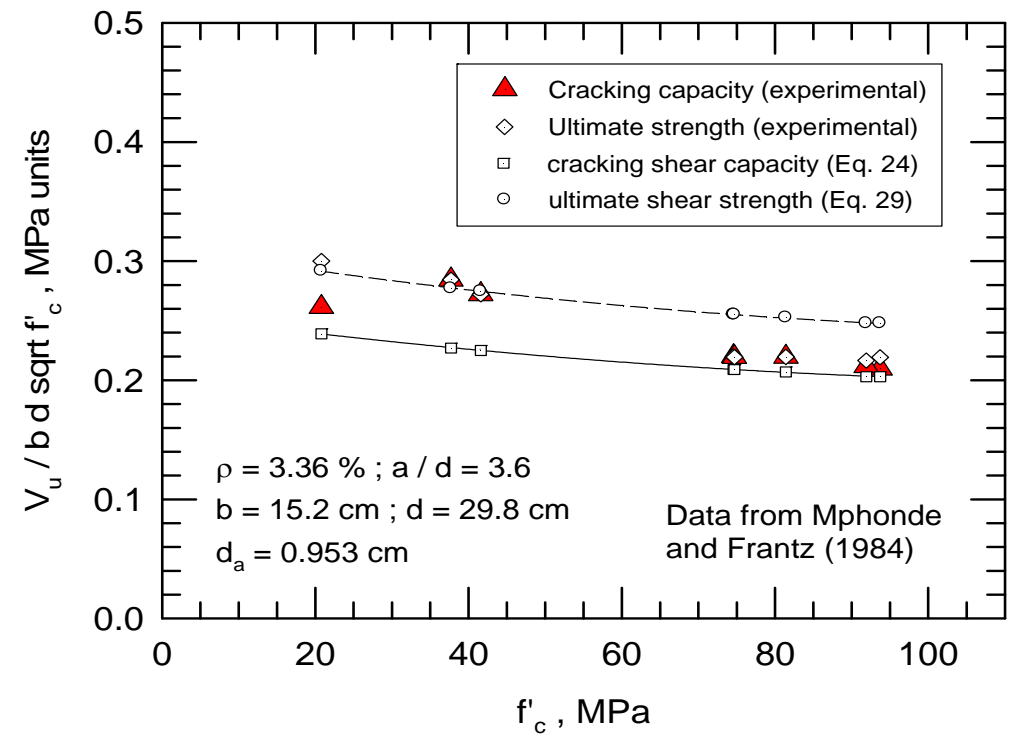

Figure (3): Experimental results are within the limits provided by the two proposed models developed for cracking shear capacity and for ultimate shear strength 


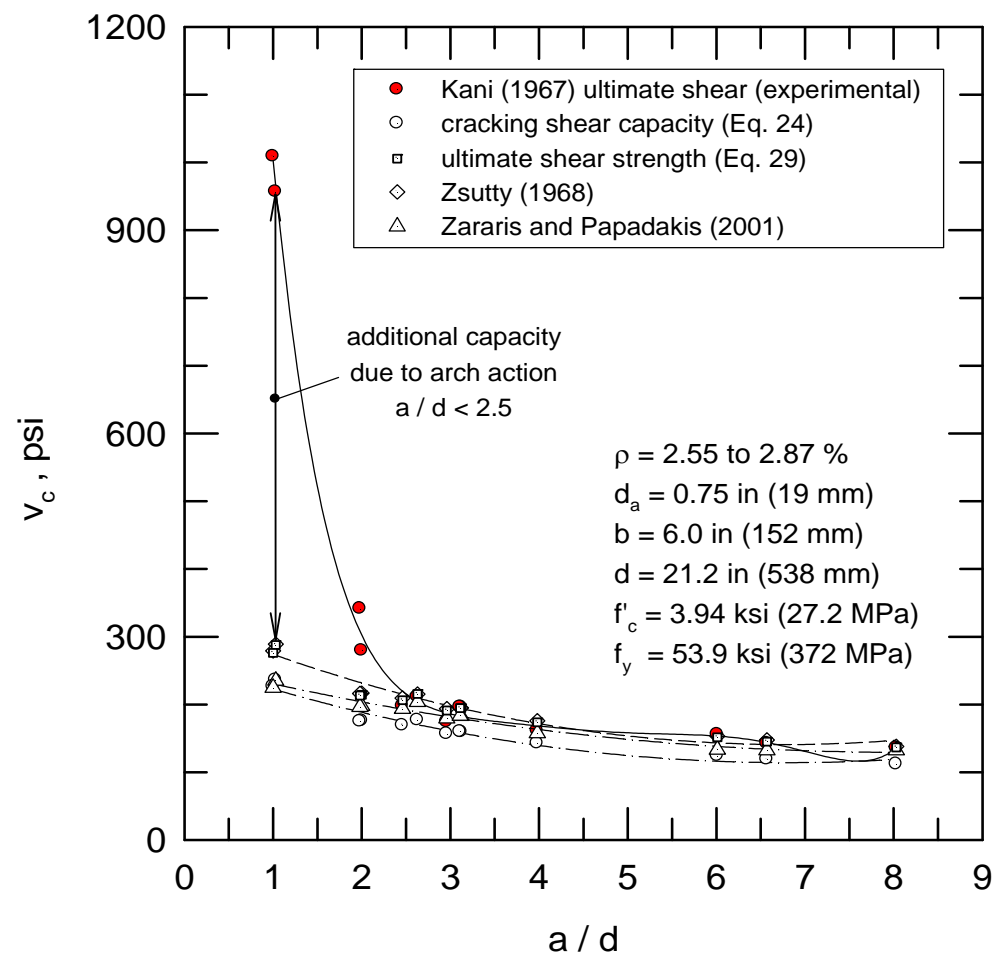

Figure (4): Comparison of the two proposed models with experimental results and models of Zsutty (1968) and Zararis and Papadakis (2001) for different values of $a / d$ from 1 to 8

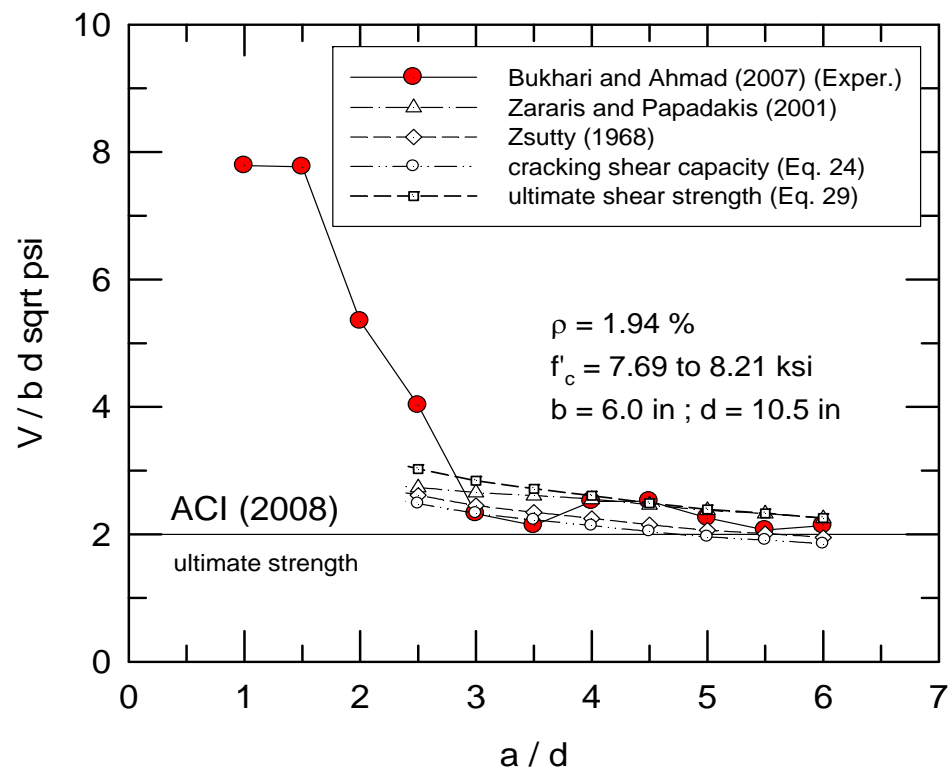

Figure (5): Comparison of the two proposed models with experimental results and models of Zsutty (1968) and Zararis and Papadakis (2001) for different values of $a / d$ from 1 to 6 


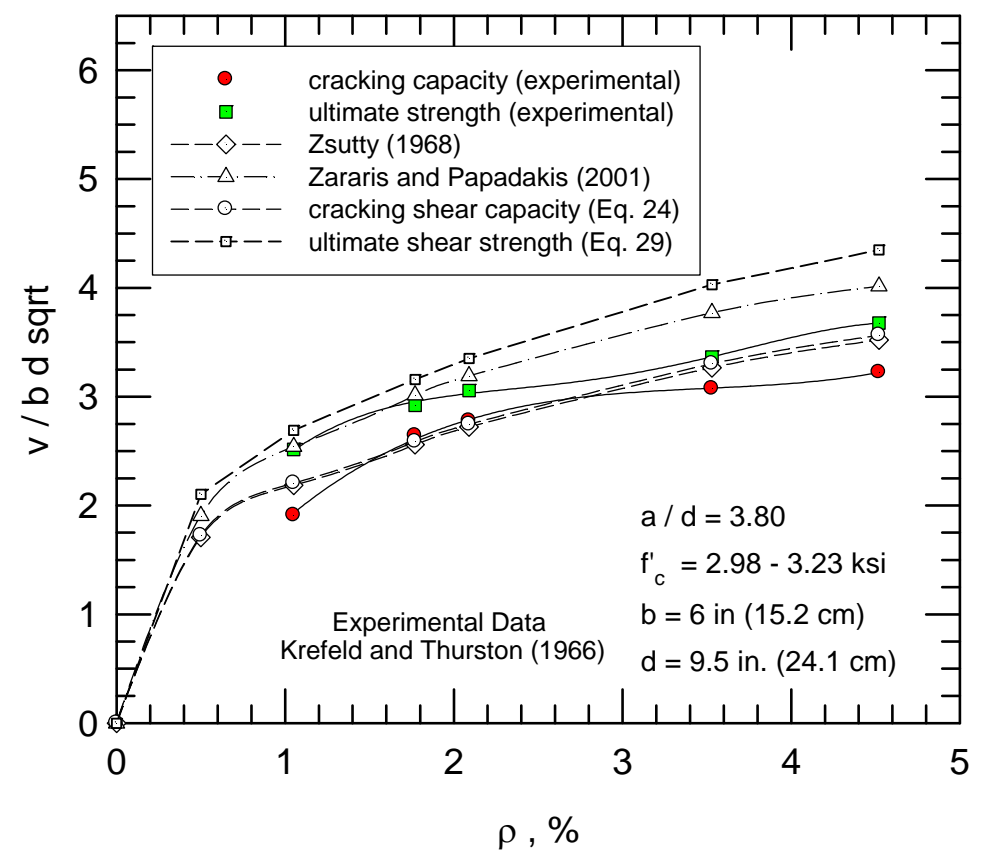

Figure (6): Comparison of the proposed models with experimental results and models of Zsutty (1968) and Zararis and Papadakis (2001) with varying $\rho$ (cracking and ultimate strengths)

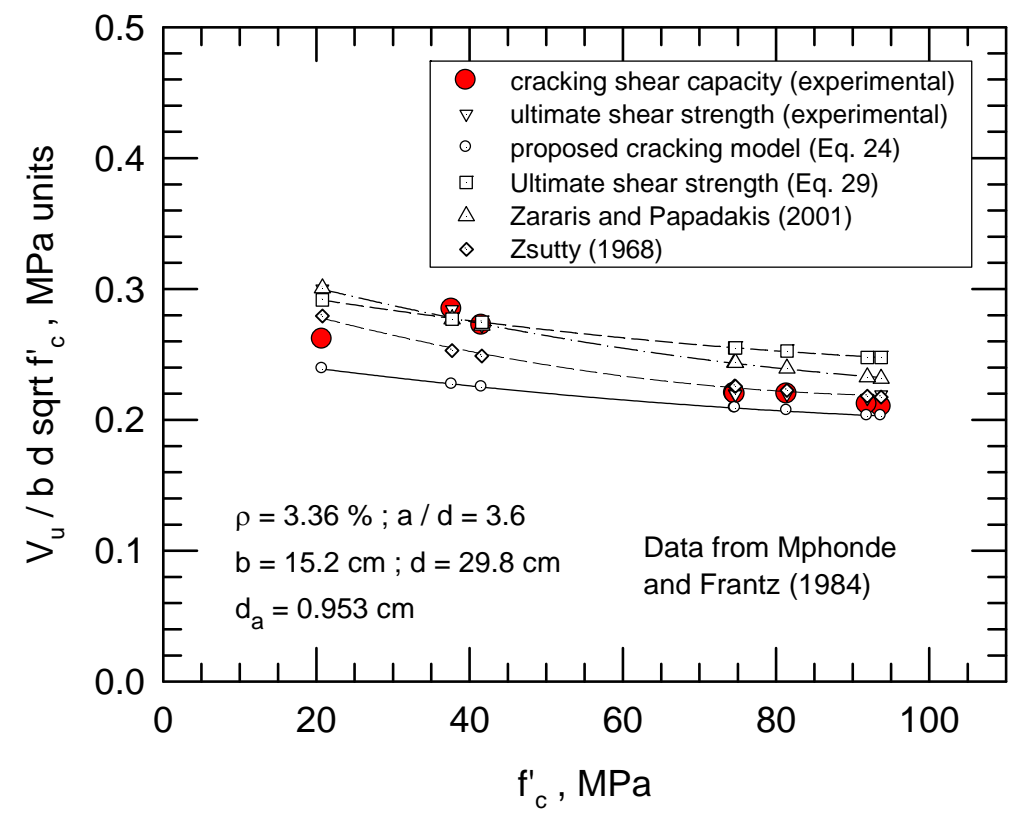

Figure (7): Comparison of the two proposed models with experimental results and with the models of Zsutty (1968) and Zararis and Papadakis (2001) for varying $f_{c}^{\prime}$ 


\section{Influence of Steel Ratio $\rho$ on Diagonal Tension Cracking and Ultimate Shear Strengths}

Figure 6 compares the variation of $V / \sqrt{f^{\prime}{ }_{c}} b d$ as a function of steel ratio $\rho$ obtained by the two proposed models for diagonal tension cracking capacity and for ultimate shear strength with experimental results (Krefeld and Thurston, 1966) as well as with the models of Zsutty (1968) and Zararis and Papadakis (2001). As can be seen, the general trend and values of the experimental results can be predicted quite reasonably utilizing the four models. These models show that the shear capacity $\left(V / \sqrt{f^{\prime}{ }_{c}} b d\right)$ generally increases with $\rho$, but the rate of increase varies significantly. The rate of increase in shear capacity is relatively small for beams with steel ratio greater than about $1 \%$ to $2 \%$. The Zsutty (1968) model again gives reasonable results because the beams of Fig. 6 have $d \leq 50 \mathrm{~cm}$. However, the Zsutty (1968) model may significantly overestimate shear capacity for large beams $(d>50 \mathrm{~cm})$ as shown later in this paper.

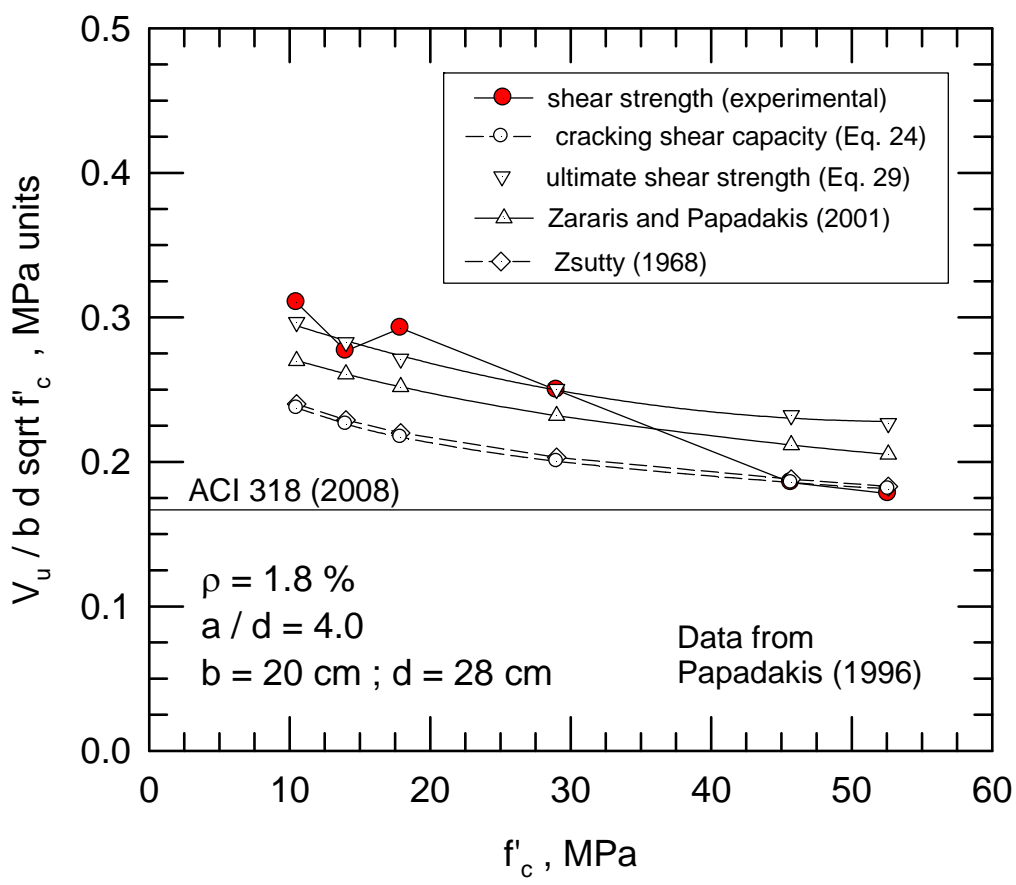

Figure (8): Comparison of the two proposed models with experimental results (Papadakis, 1996) and with the models of Zsutty (1968) and Zararis and Papadakis (2001) for varying $f_{c}^{\prime}$

Influence of Concrete Compressive Strength $f^{\prime}{ }_{c}$ on Shear Strength

Figures 7 to 9 compare the variation of $V / \sqrt{f_{c}^{\prime}} b d$ as a function of $f_{c}^{\prime}$ obtained by the two proposed models for diagonal tension cracking capacity and for ultimate shear strength of slender RC beams with three sets of experimental results as well as with the models of Zsutty (1968) and Zararis and papadakis (2001).
Figures 7 to 9, which include a wide range of concrete compressive strength, show that these models can reasonably predict the general behavior of shear capacity with $f_{c}^{\prime}$ that yield almost parallel lines for $V / \sqrt{f_{c}^{\prime}} b d$ as a function of $f_{c}^{\prime}$. Figures 7 to 9 show that the experimental results of slender RC beams are practically within the range or limits provided by the two models presented in Eq. 24 for the cracking shear 
capacity and in Eq. 29 for the ultimate shear strength (despite the relatively large scatter in the experimental results observed particularly in Fig. 9). Figure 10, however, shows that the calculated values of the cracking shear capacity are within about $10 \%$ of those experimentally measured for the cracking shear capacity of slender RC beams with $a / d>2.5$.

\section{Influence of Beam Size d on Shear Capacity}

Figure 11 compares the variations of $V / \sqrt{f^{\prime}{ }_{c}} b d$ as a function of the beam depth $d$ obtained by the two proposed models for cracking and ultimate shear strengths and experimental results of Bhal (1968) slender RC beams with depth in the range $30<d<120 \mathrm{~cm}$. As can be seen, the two proposed models and MCFT model (Appendix 3) as well as the model of Zararis and Papadakis (2001) can reasonably predict the general trend of the shear capacity with the variation of the beam size $d$ where the diagonal cracking shear capacity model (Eq. 24) provides a lower limit and the ultimate shear strength model (Eq. 29) provides an upper limit for the slender RC beams with $a / d>2.5$. Figure 11 shows that the Zsutty (1968) model, which is independent of the beam size $d$, overestimates the shear capacity for slender RC beams with depth greater than about $30 \mathrm{~cm}$ for this series of tests.

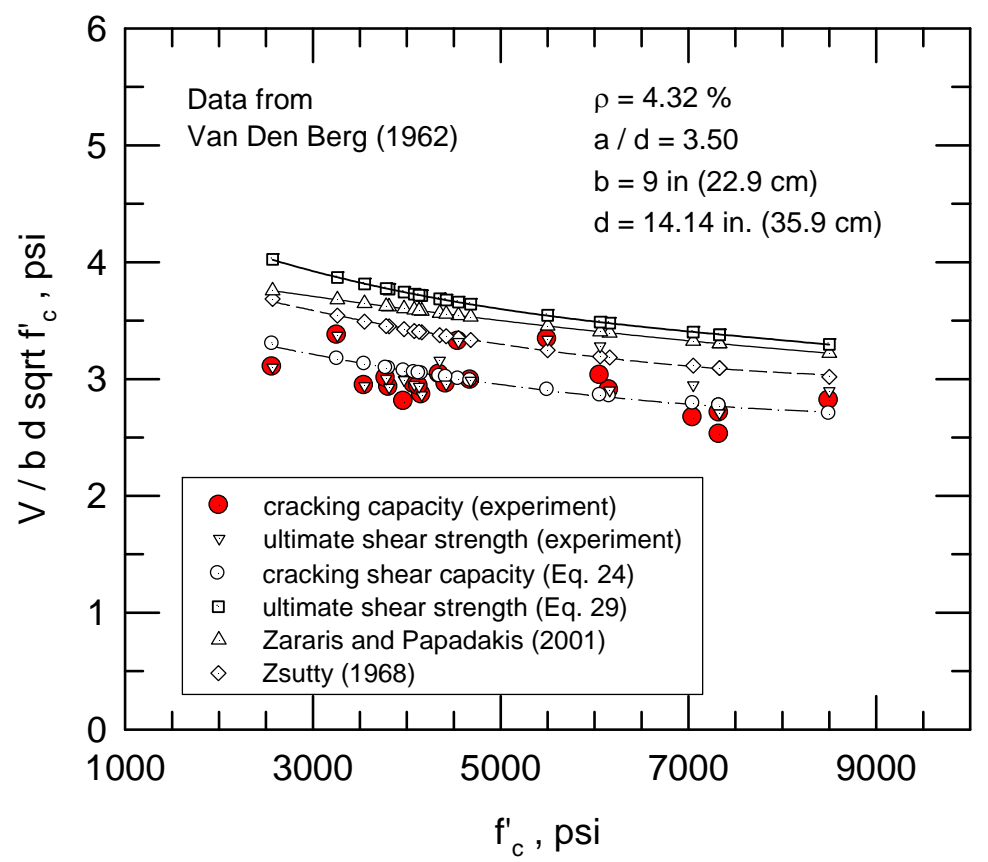

Figure (9): Comparison of the two proposed models with experimental results and with the models of Zsutty (1968) and Zararis and Papadakis (2001) for varying $f_{C}^{\prime}$

\section{SUMMARY AND CONCLUSIONS}

A method that combines dimensional analysis and statistical regression analysis for predicting the shear strength of slender reinforced concrete beams without web reinforcement taking into consideration the size effect under the combined action of moment and shear is presented. This method incorporates the modified Buckingham-PI theorem (Butterfield, 1999) to formulate general expressions for the shear capacity 
under different conditions. Two models are proposed for predicting the cracking shear capacity at the formation of diagonal tension cracks and the ultimate shear strength. Comparison of the results of the two proposed models with several sets of existing experimental results supports the validity of the two proposed models in predicting and explaining the observed behavior of slender RC beams $(a / d \geq 2.5)$ without web reinforcement and also shows that dimensional analysis can be used to give reasonably well predictions and sufficiently accurate method of analysis. This study shows that the large variations in the experimental results of shear strength of slender RC beams $(a / d>2.5)$ defined at the formation of diagonal tension cracks can be explained by the variations of the concrete tensile strength.

This study also shows that the large variations in the experimental results of ultimate shear strength of slender RC beams $(a / d>2.5)$ can be explained by the variations of the concrete splitting strength.

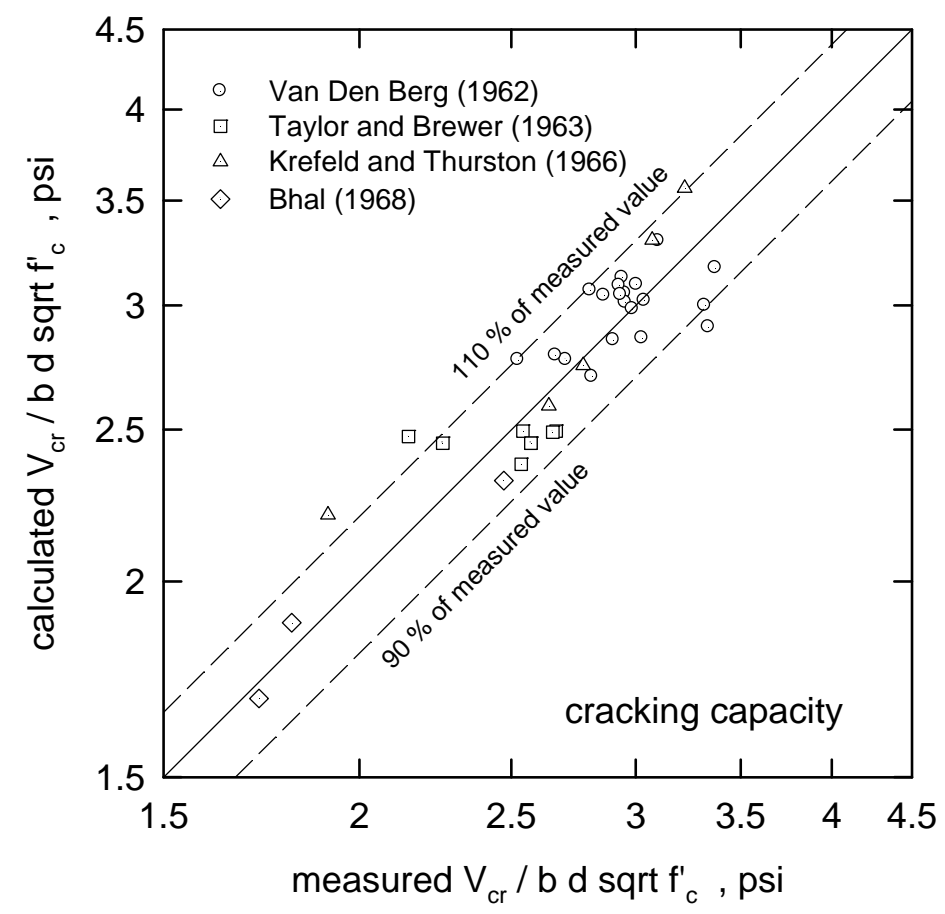

Figure (10): Comparison of the calculated cracking shear capacity with experimentally measured shear capacity for slender RC beams with different values of $a / d>2.5$

The model proposed for the cracking shear capacity at the formation of diagonal tension cracks provides a lower limit (within only about 10\%) for the experimentally measured values and the model proposed for the ultimate shear strength provides an upper limit for the experimentally measured values.

\section{Appendices}

\section{1- Model of Zararis and Papadakis (2001)}

Zararis and Papadakis (2001) suggested the following expression for evaluating the ultimate shear strength for slender RC beams without web reinforcement having $a / d \geq 2.5$. 


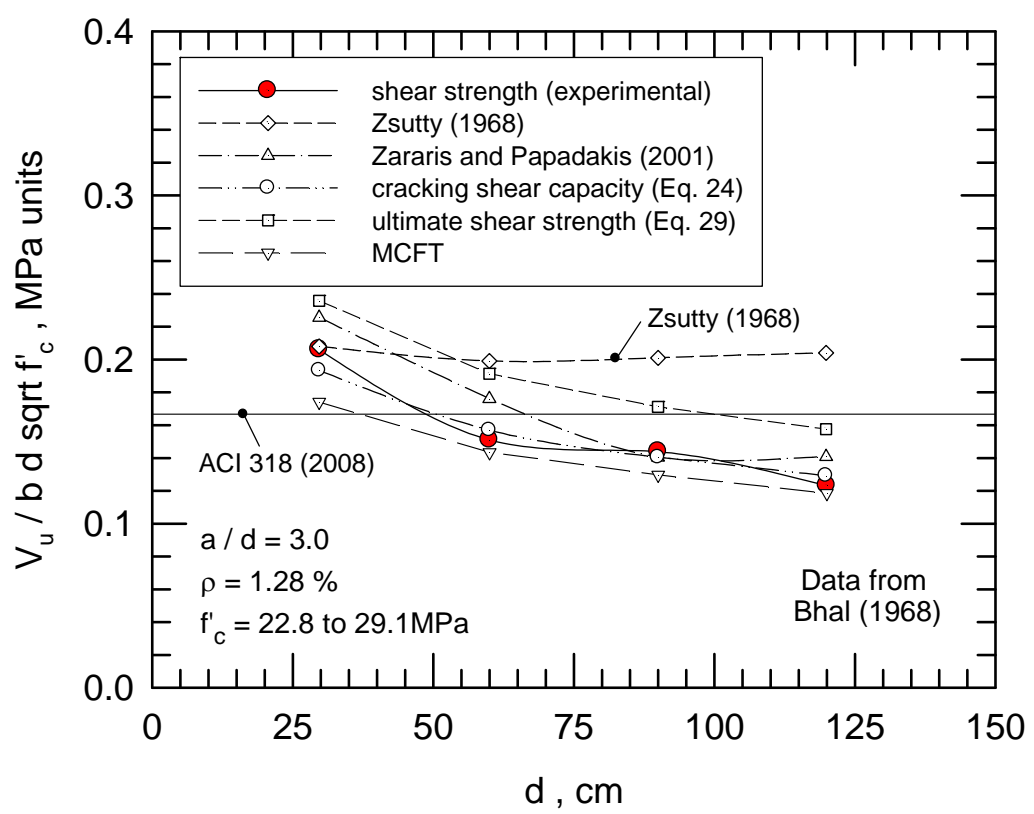

Figure (11): Comparison of the two proposed models with experimental results and MCFT model and the models of Zsutty (1968) and Zararis and Papadakis (2001) for varying $d$

$v_{u}=\frac{V}{b d}=\lambda_{d} \frac{c}{d} f_{c t}$

$\lambda_{d}=\left(1.2-0.2 \frac{a}{d} d\right) \geq 0.65$

$\left(\frac{c}{d}\right)^{2}+600 \frac{\rho}{f_{c}^{\prime}} \frac{c}{d}-600 \frac{\rho}{f_{c}^{\prime}}=0$

$$
f_{c t}=0.30\left(f_{c}^{\prime}\right)^{2 / 3}
$$

where $d$ is in meters and $f_{c}^{\prime}$ in MPa. This model was developed based on the concrete splitting strength of compression zone above the neutral axis in the shear span. The Zararis and Papadakis (2001) model may also be rewritten as follows: $\frac{v_{u}}{\sqrt{f_{c}^{\prime}}}=0.30 \lambda_{d}\left(\sqrt{\left(300 \frac{\rho}{f_{c}^{\prime}}\right)^{2}+600 * \frac{\rho}{f_{c}^{\prime}}}-300 \frac{\rho}{f_{c}^{\prime}}\right)\left(f_{c}^{\prime}\right)^{1 / 6}$

\section{2- ACI Code Formula (ACI 318-08)}

The ACI Code (ACI 318-08) has accepted the following empirical bilinear expression as the nominal shear strength at which diagonal flexure-shear cracking develops in beams without web reinforcement. 


$$
\begin{aligned}
& \frac{V}{b d \sqrt{f^{\prime}{ }_{c}}}=\left(1.90+2500 \frac{\rho V d}{M \sqrt{f^{\prime}{ }_{c}}}\right) \leq 3.5 \quad \text { [in psi units] } \\
& \frac{V}{b d \sqrt{f^{\prime}{ }_{c}}}=\left(0.16+17 \frac{\rho V d}{M \sqrt{f^{\prime}{ }_{c}}}\right) \leq 0.29 \quad \text { [in MPa units]. }
\end{aligned}
$$

The ACI Code (ACI 318-08) has also allowed the use of a simplified expression as follows:

$$
\begin{array}{ll}
\frac{V}{b d \sqrt{f^{\prime}{ }_{c}}}=2 & \text { [in psi units] } \\
\frac{V}{b d \sqrt{{f^{\prime}{ }_{c}}^{*}}=\frac{1}{6}} & \text { [in MPa units]. }
\end{array}
$$

\section{3- Model of the Modified Compression Field Theory (MCFT) (1986)}

In the modified compression field theory MCFT (Vecchio and Collins, 1986), the behavior of reinforced concrete is evaluated by considering equilibrium, compatibility and stress-strain relationships that include an average concrete tension component to the concrete stress-strain relationship (Bentz and Collins, 2006). The MCFT was used as the basis for the shear provisions in the Canadian Standard Association (CSA 2004 A23.3-04) and the American Association of State Highway and Transportation Officials LRFD bridge design specifications (AASHTO, 2004).

The MCFT is formulated in terms of average stresses and requires a check to ensure that the loads resisted by the average stresses can be transmitted across the crack. For members without transverse reinforcement, the local stresses at cracks always

\section{NOTATION}

$a=$ shear span

$a / d=$ shear span-to-depth ratio

As $=$ area of tension reinforcement

$b=$ width of beam

$d$ = effective depth of beam control the capacity of the member; the average stress calculation is used only for estimating the inclination of the critical diagonal crack (ACI-ASCE, 1998). According to the MCFT model, the shear strength of RC members without web reinforcement may be expressed as follows:

$v=\frac{V}{b_{w} d_{v}}=\beta \sqrt{f^{\prime}{ }_{c}}$

where $\beta$ is a function of the size effect $s_{x e}=s_{z} 35 /\left(15+a_{g}\right)$ and strain $\varepsilon_{x}$ that can be expressed for reinforced concrete beams (ACI-ASCE 1998) as follows:

$\varepsilon_{x}=\frac{M / d_{v}+0.5 V \cot \theta}{A_{s} E_{s}}$.

The two proposed models are compared with the MCFT models in terms of the shear capacity $V / b d \sqrt{f^{\prime}{ }_{c}}$ as a function of the steel ratio $d$ (Fig. 11). The MCFT predictions were carried out according to the general procedure described in Bentz and Collins (2006) using a spread sheet; the strain $\varepsilon_{X}$ and the angle $\theta$ of the average principal compression were adjusted until the value of $\beta$ from the average shear stress is equal to the value of $\beta$ from the local shear stress and the strain $\varepsilon_{x}$ is equal to that calculated from Eq. 38 .

$D_{1}, D_{2} \ldots$ etc. $=$ primary dimensions

$f_{c}^{\prime}=$ cylindrical compressive strength

$f_{c t}^{\prime}=$ concrete tensile strength

$f_{s p}=$ concrete splitting strength

$f_{y}=$ yield strength of longitudinal steel

$h=$ total depth of beam

$L=$ length 
$m$ = number of independent primary dimensions

$M=$ mass

$n=$ number of the basic variables

$T$ = time

$v_{c r}=$ diagonal cracking capacity

\section{REFERENCES}

AASHTO LRFD. (2004). "Bridge Design Specification and Commentary.” $3^{\text {rd }}$ Edition, American Association of State Highway Transportation Officials, Washington, D.C., 1264 pp.

ACI Committee 318. (2008). "Building Code Requirements for Structural Concrete (ACI318-08) and Commentary (318R-08).”American Concrete Institute, Farmington Hills, Mich., 430 pp.

ACI-ASCE Committee 445 on Shear and Torsion. (1998).

"Recent Approaches to Shear Design of Structural Concrete". ASCE Journal of Structural Engineering, 124 (12), 1375-1417.

Adebar, P., and Collins, M.P. (1996). "Shear Strength of Members without Transverse Reinforcement," Canadian Journal of Civil Engineering, 23 (1), 30-41.

Appa, Rao G., and Injaganeri, S.S. (2011). "Evaluation of Size Dependent Design Shear Strength of Reinforced Concrete Beams without Web Reinforcement". Sadhana Journal, June, 36 (3), 393-410.

Arslan, G. (2008). "Cracking Shear Strength of RC Slender Beams without Stirrups". Journal of Civil Engineering and Management, 14 (3), 177-182.

Arslan, G. (2010). "Shear Strength of Reinforced Concrete Slender Beams". Proceedings of the ICE - Structures and Buildings, 163 (3), June, 195-205.

Arslan, G. (2012). "Diagonal Tension Failure of RC Beams without Stirrups". Journal of Civil Engineering and Management, 18 (2), 217-226.

Bazant, Z. P., and Kim, J. K. (1984). "Size Effect of Longitudinally Reinforced Beams". ACI Journal, 81 (5), 456-468. $v_{u}=$ ultimate shear strength

$V_{1}, V_{2} \ldots$ etc. $=$ basic variables

$\rho=$ longitudinal reinforcement ratio

$\xi=$ beam size factor

Bazant Z. P., and Kazemi, M.T. (1991). "Size Effect on Diagonal Shear Failure of Beams without Stirrups". ACI Structural Journal, (3), 268-274.

Bentz, E.C., and Collins, M.P. (2006). "Development of the 2004 Canadian Standards Association $\{C S A\}$ A23.3: Shear Provisions for Reinforced Concrete". Canadian Journal of Civil Engineering, 33, 521-534.

Bentz, E.C., Vecchio, F.J., and Collins, M.P. (2006). "Simplified Modified Compression Field Theory for Calculating Shear Strength of Reinforced Concrete Elements". ACI Structural Journal, 103 (4), JulyAugust.

Butterfield, R. (1999). "Dimensional Analysis for Geotechnical Engineering.” Geotechnique, 49 (3), 357366.

Clark, A.P. (1951). "Diagonal Tension in RC Beams". ACI Journal, 23 (2), 145-156.

Collins, M.P., and Kuchma, D.A. (1999). "How Safe Are Our Large, Lightly Reinforced Concrete Beams, Slabs and Footings?” ACI Structural Journal, 96 (4), 282290.

CSA Committee A23.3 (2004). "Design of Concrete Structures (CSA A23.3-04)." Canadian Standards Association, Mississauga, 214 pp.

Hsu, T. T. C., Mau, S. T., and Chen, B. (1987). "A Theory of Shear Transfer Strength of Reinforced Concrete". ACI Structural Journal, 84 (2), 149-160.

Kani, G. N. J. (1967). "How Safe Are Our Large Reinforced Concrete Beams?" ACI Journal, 64 (3), May-June, 128-141.

Kim, J.K., and Park, Y.D. (1996). "Prediction of Shear Strength of Reinforced Concrete Beams without Web Reinforcement". Materials Journal, 93 (3), 213-222. 
Krefeld, W. J., and Thurston, C. W. (1966). "Contribution of Longitudinal Steel to Shear Resistance of Reinforced Concrete Beams". ACI Journal, 63 (3), 325-344.

Leonhardt, F., and Walther, R. (1962). "Beiträge zur Behandlung der Schubprobleme in Stahlbetonau". Beton-und Stahlbetonbau (Berlin), March and June, 141-149.

MacGregor, J.G. (1997). "Reinforced Concrete Mechanics and Design,” $3^{\text {rd }}$ Edition, Prentice-Hall, Eaglewood Cliffs, N.J.

Mphonde, A. G., and Frantz, G. C. (1984). "Shear Tests of High- and Low Strength Concrete Beams without Stirrups". ACI Journal, 81 (4), 350-357.

Papadakis, G. (1996). "Shear Failure of Reinforced Concrete Beams without Stirrups". PhD Dissertation, Department of Civil Engineering, Aristotle University of Thessaloniki, Thessaloniki, Greece (in Greek).

Phatak, D.R., and Dhonde, H.B. (2003). "Dimensional Analysis of Reinforced Concrete Beams Subjected to Pure Torsion.” Journal of Structural Engineering, ASCE, 129 (11), November, 1559-1563.

Rebeiz, Karim S., Fente, Javier, and Frabizzio Michael. (2000). "New Shear Strength for Concrete Members Using Statistical and Interpolation Function Techniques". The $8^{\text {th }}$ International Specialty Conference on Probabilistic Mechanics and Structural Reliability. PMC2000-279.

Regan, P. E., and Yu, C. W. (1973). "Limit State Design of Structural Concrete". Chatto and Windus, London.

Reineck, K.H. (1991). "Ultimate Shear Force of Structural Concrete Members without Transverse Reinforcement Derived from a Mechanical Model". ACI Structural J., 88 (5), 592-602.
Reineck, K-H., Kuchma, D.A., Kim, K.S., and Marx, S. (2003). "Shear Database for Reinforced Concrete Members without Shear Reinforcement”. ACI Structural Journal, 100 (2), 240-249.

Rebeiz, K.S., (1999). "Shear Strength Prediction for Concrete Members". The Journal of Structural Engineering, 125 (3).

Russo, G., Somma, G., and Mitri, D. (2005). "Shear Strength Analysis and Prediction for Reinforced Concrete Beams without Stirrups." ASCE Journal of Structural Engineering, 131 (10), 66-74.

Shioya, T., Iguro, M., Nojiri, Y., Akiayma, H., and Okada, T. (1989). "Shear Strength of Large Reinforced Beams". Fracture Mechanics: Application to Concrete, SP-118, V.C.

Taylor, H. P. J. (1972). "Shear Strength of Large Beams". Journal Structural Division, ASCE, 98 (11), 24732490.

Van Den Berg, F.J. (1962). "Shear Strength of RC Beams without Web Reinforcement, Part 2-Factors Affecting Load at Diagonal Cracking". ACI J., 59(11), 15871600.

Vecchio, F. J., and Collins, M. P. (1986). "The Modified Compression Field Theory for Reinforced Concrete Elements Subjected to Shear". ACI J., 83(2), MarchApril, 219-231.

Zararis, P.D., and Papadakis, G. (2001). "Diagonal Shear Failure and Size Effect in RC Beams without Web Reinforcement", ASCE Journal of Structural Engineering, 127 (7), 733-742.

Zsutty, T. C. (1968). "Beam Shear Strength Prediction by Analysis of Existing Data." ACI Journal, 65 (11), 943951.

Zsutty, T. C. (1971). "Shear Strength Predictions for Separate Categories of Simple Beam Tests”. ACI Journal, Proceedings, 68 (2), 138-143. 